\title{
DEVELOPMENT OF TOURISM IN STARA ZAGORA - A PREREQUISITE FOR SUSTAINABLE DEVELOPMENT IN THE REGION
}

\author{
A. Gidikova* \\ $\mathrm{PhD}$ student, Department of Regional Development, Faculty of Economics, \\ Trakia University, Stara Zagora, Bulgaria
}

\begin{abstract}
For the development of the cities and regions around them, and in particular where there is a large number of working population, the creative tourist sites, which have their specificity and modernity with relevant innovations and stimuli in the public space, play significant role, thus contributing for development of tourism in the region and in practice create added economic value in the cultural and tourist industry.
\end{abstract}

Keywords: Tourism, innovations, regional economy, sustainable development, sustainable model

\section{TOURISM IN DEVELOPMENT OF REGIONAL ECONOMY OF URBAN AREAS.}

One of the fastest growing sectors in the big cities and the developed economic regions is tourism, which is a consequence of the global competition, the acquisition of new investments and, first of all, the increasing tourist consumption in these regions. The rapid development of the tourism industry is also due to the availability of valuable natural resources and a variety of favorable factors in a rather small geographical area. The UN's urban population growth projection is $61 \%$ by 2030 , or 5 billion people, gives exclusivity to tourism, making it a major factor affecting the integrated development of cities

Analyzing data from recent statistical surveys, urbanization is the reason for the rapid development of tourism in economically developed regions. The number of tourist arrivals in destinations such as New York, Paris, London and Beijing, Moscow and other capitals and big cities increased by more than $30 \%$. According to UN statistics, about 5 billion of the world's population is expected to live in major cities by 2030 (1). This estimate

\footnotetext{
*Correspondence to: Anastasia Gidikova, PhD student, Department of Regional development, Faculty of Economics, Trakia University, Stara Zagora, Bulgaria, Post code: 6000, e-mail: anastasia.gidikova@abv.bg
}

for Europeans and North Americans is about $80 \%$ of the total population (2). These numbers by themselves characterize the rapid development of major cities and the regions around them, with parallel developments of tourism. However, it should be emphasized that urbanized regions are provoking interest among tourists not only because of their welldeveloped infrastructure, which ensures the development of the tourism industry, but also because of the numerous leisure activities and special events that they organize. Having in mind the above mentioned cities, it should be emphasized that they have highly developed economies and they offer innovative tourism products and services, which in return attract extremely large tourist flows. Analyzes of such regions in Bulgaria, such as Sofia, Plovdiv, Burgas, Varna, Stara Zagora, prove a process of shifting from the so called "service oriented economy" to the "experience oriented economy". Within the dynamic environment of the tourism development in these regions, the focus is placed on:

- Innovative tourist attractions and animation;

- National tourism specifics;

- Authentic, typical and national tourist offer;

- Diversification of tourist products;

- Thematic tourist products in the field of cultural heritage;

- Events of contemporary culture;

- Protected areas, Balneo and SPA tourism;

- Historical, sports and religious tourism. 
Therefore the development of tourism in major cities and regions around them should be regarded as a complex of factors and events of great importance to urban centers and their economy, including tourism, creating opportunities for local residents by increasing jobs and income. It should be emphasized that possessing innovations, which are necessary for the tourism to become more attractive can successfully make the city and the region a preferred tourist destination for tourism.

The main positives that associate with the region of Stara Zagora as a preferred tourist destination can be summarized in the following directions, factors and elements:

- Good location and favorable geographical location;

- Easy access with good infrastructure;

- Natural resources - mineral springs, mountains, forests, rivers;

- Cultural and historical sites;

- Favorable climate;

- Practicing various types of tourism in a relatively compact area and small distances;

- Created traditions of organizing events, festivals etc. innovative in the field of all arts.

In conditions of growth and transformation of cities and regions, it is of a great importance to provide tourists with products and experiences that meet their expectations and will no doubt meet the increasing consumer demand and requirements. This is precisely what concerns the particularities of tourism innovations in the big cities and the regions around them. Innovations are the offering of new tourist products, with their consumption achieving a number of social and economic goals for the local population. Last but not least, tourism creates dynamics in cities and economically developed regions through new models of change and innovation in urbanized environments. It should be noted that tourism connects people, creates relationships between them and teaches them how to live in close connections to each other. This is an industry that is one of the main factors and a sustainable model for rapid economic development in many countries and regions and plays an important role in terms of employment, income and maintenance of high quality infrastructure and public services.

An important feature of tourism is its ability through competitive approaches and, in this sense, destinations that focus on offering innovative products that are increasingly specialized in order to gain market positions while also reflecting innovative change, characteristic of the city and the region. Therefore, the tourism industry needs to come up with innovative strategies that ensure a sustainable image of the city and the region around it, significant revenue, and added value for locals.

Strategic goals for sustainable tourism development in Stara Zagora region can be formulated through the following actions:

- Promoting a positive image of tourism and raising the profile of the town of Stara Zagora and the region as a year-round destination with characteristic, preserved cultural traditions and nature;

- Increasing the competitiveness of the city of Stara Zagora and the region by improving the quality of tourist products, developing a strong brand of the destination and product specialization and diversification;

- Introduction of international standards and good European practices, implementation of innovative products, information and communication technologies in line with the requirements of tourist demand;

- Promoting the internal market - structuring of regional, municipal and local policies to support the development of tourism in the area and positioning of specific products meeting the domestic market trends;

- Encouraging the role of tourism as a decisive factor for the development of the labor market by improving the qualifications, performance and adaptability of the workforce;

- Taking measures to position the city of Stara Zagora and the region as a tourist destination in a higher class on the domestic and foreign tourism market with high quality of the offered tourist product and added value;

- Increasing the share of specialized types of tourism leading to year-round and more intensive use - Balneo (medical SPA), SPA and wellness, cultural (in all its forms historical, archeological, ethnographic), eco and rural tourism, adventure, congress, hunting, golf, wine and gourmet;

- Promoting integrated regional tourism development in the city of Stara Zagora and the region by forming appropriate organizational structures, coordinating the 
supply and implementation of regionally differentiated state tourism policy;

- Conservation and sustainable use of tourism resources, including natural, cultural and anthropogenic;

- Improvement of tourist attractions and related infrastructure;

- Increasing the protection, rights and security of users of tourist services;

- Encouraging cooperation between central and local level institutions and representatives of the tourism industry to create opportunities for partnership development;

- Improving the quality of education and training in tourism in accordance with the needs of the sector in the city of Stara Zagora and the area and development of the labor market.

By identifying these actions, the existing problems faced by cities in different regions of the world, in Bulgaria and in particular the Stara Zagora region, are taken into account. First is the growing number of tourists in cities in the context of responsible and sustainable tourism. In addition, the pace of development must be adapted to the quality of life of the local population. The links and interdependencies between tourism development strategies and urban and regional development should be clarified as part of the decision-making process for development. Last but not least, it is the combination of appropriate information and communication technologies that make cities in the regions more competitive, sustainable and accessible, both for locals and for tourist. Innovative ways for measuring of the economic impact of tourism on cities and regions should be implemented. Lastly, practical action must be taken to reduce the environmental impact of tourism and to promote the benefits of ecotourism

According to studies, approximately $65 \%$ of Europe's population travels at least once a year as a result of increased incomes and spare time (3). In this connection, large cities should focus on offering new and attractive products that can be the basis of art, for example. Theatrical festivals, international competitions, concerts are important for promoting the cities in which they take place.

As a result of conducted research, there are several essential elements that highlight the peculiarities of the repositioning of a tourist destination of the city of Stara Zagora and the region and in general Bulgaria. First, much of the regulation relating to the development of a tourist destination or parts of it concerns the need of innovations in tourism, and in particular in tourist products. The National Strategy for Sustainable Development of Tourism in Bulgaria 2014 - 2030 states that modern tourists are strongly interested in innovative tourism products that combine the standard tourist service with a specific product corresponding to their interests (4). However, innovation remains recognizable only as a concept, without clearer guidelines and tools for its practical implementation and validation in tourism. The updated version of the Strategy (5) notes some progress on this topic, as there are some mentioned factors that limit innovation (keeping prices low, lacking partnerships etc.).

Second, in Bulgaria, according to the registry of the Ministry of Tourism (6) there are only two officially registered organizations for management of tourist regions (known in the English language literature as DMO Destination Management Organization): the Rhodope Tourist Area Management Organization and the Organization for Management of Varna Black Sea Tourist Region. The limited number of these legal entities, the lack of experience in their operation, as well as the many requirements related to their establishment and operation, also complicate the process of repositioning the tourist destination, following the global tourist trends and competitiveness. It is these organizations that are able to play a key role in promoting the creation and implementation of product innovations by the various stakeholders in the tourist destination.

Third, today's tourists seek, above all, the feeling that they have experienced something special during their stay in the tourist destination, rather than simply purchasing a product (7). This is the main reason for the tourist destination of cities and regions in Bulgaria to be repositioned through innovations. They are the ones to turn the tourist product into an experience and to present new, unknown aspects of the destination. This "novelty" is a significant attraction for tourists seeking new forms of entertainment, enrichment, relaxation etc. This is a clear sign of the transition from the 'service oriented economy' to the 'experience oriented economy', i.e. the focus is on tourist 
attractions, animation and authentic activities for the destination. Therefore, innovation in the tourist product can be reflected in inclusion of elements in the product that tourists would consider being of additional benefit to them in terms of experiences such as diversification based on cultural events, historical sites, nature parks, religious temples, SPA and wellness procedures, extreme experiences and more.

Fourth, the tourism product, thanks to its services, is distinguished by its intangibility. As a result, consumers need to use more senses to fully consume this product, though this may be a more indirect path. In this way, new areas of influence such as aroma, taste, design, sound, color, etc. are opened up to innovations, which creates a prerequisite for influencing the emotional state of tourists. This in return creates a new opportunity to generate added value for the users of the product during their stay.

Fifth, talking about innovation, even in the tourism product, we should have in mind the topic of modern technologies that are actively penetrating every sphere of life and economy. They allow users to be impacted in new ways.

For the last 5 years Stara Zagora has been one of the most popular tourist destinations in Bulgaria. Due to the climatic peculiarities, there is a tendency the active tourist season in the summer to be reduced, as a result of which the city and the region begin to specialize in offering urban tourist trips. According to tourists, the country's historical heritage as well as the events that are organized in different destinations, offer much more interesting experiences than traditional weekends. In this connection, the growth of the number of the tourists, which takes into account the tourism industry is precisely due to the development of urban innovative and event tourism. Analyzing tourism in ours and European cities as a whole, it becomes obvious that overall growth is approximately 5\% per year. There is an increase in hotel bookings in cities, especially in destinations such as the city and the region of Stara Zagora during periods of cultural events, festivals and exhibitions, the growth being directly proportional to the innovative way of combining events and animation. Undoubtedly, the result is visible not only in the growth of the tourism industry, but also in increasing the employment and benefits of the local population. Analyzing world statistics for cities and regions such as London, Paris and Berlin, one can clearly see that these are the three most popular European cities for tourist visits in the last few years. However, looking at Barcelona and Prague, we see even higher tourist growth rates of over $10 \%$ annually. The most visited cities in the world in 2014 by number of international tourist arrivals are: London (18.82 million), Bangkok (18.24 million), Paris (16.06 million), Dubai (14.26 million), Istanbul (12.56 million), New York (12.27 million), Singapore (11.88 million) and Kuala Lumpur (11.12 million), Seoul (10.35 million) and Hong Kong (8.66 million), (8). Bulgaria is represented by Sofia, which ranks 89th out of 132 cities in the survey of the Master Card Global Destination Cities Index for the most preferred destinations for international tourism. It should be noted that the Bulgarian capital is moving two positions forward in two years from 91st place. The MasterCard Global Destinations Cities Index survey includes the 132 most visited cities in the world by tracking travel and providing a thorough analysis of tourist flows, showing the importance and popularity of world cities in their role as welcoming tourist destinations and generators of economic growth.

The forecasts for the development of tourist destinations related to the economic development of cities as a result of the development of the tourism industry is of particular interest (9). In the first place, the experiences of emotions by tourists is what will lead to more accessible (physical and economical) forms of entertainment, with a focus on people from different countries and the relationships between them. Another focus is entertainment and demand, which shifts the traditional focus from the price of tourist goods and services. In addition, interest in ethics increases in tourism, leading to sustainability and to increasing corporate social responsibility, which is undoubtedly globally important for people. In addition, the staff involved in tourist business must be more responsible, with adequate digital skills and capacity to work in intercultural environment in the context of the wide range of services in urban tourism - an information-intensive sector, however, lacking an adequate transformation of information flows into knowledge. Therefore, there is an important need to create tools and systems that coordinate and manage the available knowledge in the value chain in tourism. The way in which stakeholders exchange 
knowledge and information, influences the strategic change and sustainable development of the respective destinations.

In this connection and based on global and national surveys, the priorities for the development of a tourist destination, such as the city of Stara Zagora and the region that successfully develops tourism, are summarized in the following directions:

- Economic impact of tourism;

- Management and strategic planning;

- Promotion and marketing;

- Development of tourism products;

- Human resources;

- Responsible tourism - cultural heritage and the natural environment;

- Innovation;

- Visitor experiences.

Effective management of an urban tourist destination, improving its competitiveness and quality of life for local residents means managing economic, social and environmental situation in an environment with high levels of insecurity and threats. This is the only way to develop long-term strategies and to guarantee the development of tourist destinations without taking into account, for example, climate change or scarcity of resources. Obviously, the old governance models need to be revised in order to meet new environmental principles, values of societies and high consumer demands.

\section{SPECIFICITY OF CITIES AND REGIONS AROUND THEM - AN OPPORTUNITY FOR INNOVATION AND IDENTITY}

The city is a privileged place for production and consumption of cultural heritage for the purposes of the tourism industry. Urban development is accelerated by the interconnections between the cultural and leisure industries. The appeal of the cities and the regions around them is based on local tourist attractions and sites that combine their history and cultural heritage, as well as the links between innovations and creativity, in a more universal and global aspect. Creativity refers not only to the physical and geographical characteristics of particular places, but also to the processes of interaction that favor the creation of cultural and social innovations. In this case, creativity is a prerequisite for effecting change and creating opportunities for development of the region. Innovations can also be presented as the ability to generate new, original ideas based on knowledge. Innovation, together with creativity, is regarded as a basic condition for the ability to develop new and original solutions as a prerequisite for abandoning old ways of thinking or perspectives and to create new, surprising connections between data sharing and structures (10). Identity awareness of cities and regions is an opportunity for development of urban tourism and the corresponding increase in tourist flows to the certain destinations. This importance is emphasized in the context of creativity - a starting point for cities to achieve economic growth through the provision of tourist services and the opportunity to attract more visitors, in the context of the competition of metropolises and other major cities.

In specialized literature there are two sets of scholarly opinions concerning the discussed topics - the first indicates that local economies are highly dependent on urban development; in opposite to the second which regard the local economies as contributors to urban development (11). Specific places in cities increase the importance of the production and consumption of specific, individual services (12). In this context, cities are privileged locations for the production and consumption of tourist goods and services that are cultural in nature but also have opportunities for social innovations. In this way, urban tourism, regarded as a kind of cultural tourism, with its economic and social effects, contributes to the development of cities. In underdeveloped tourist cities in the process of accelerated urbanization, the benefits of cultural tourism reveal a potential acceleration of economic development. As a result, a number of beneficial effects occur for communities and their cultures (13).

Considering the specifics of the city of Stara Zagora and the region, the perspectives for sustainable tourism development in the Stara Zagora district are based on several directions:

- Based on the expected increase in the consumption of health services, due to aging of the population, Stara Zagora region to be strongly positioned on the market for balneo, SPA and wellness tourism;

- Development of health tourism with medical centers as specialized medical SPA centers that combine SPA experience and treatment. 
- The central location and the enormous resource of natural healing mineral waters combined with modern hotels is a serious reason for the District of Stara Zagora to become a "Health Center in Bulgaria"

- Organization of regular annual events, festivals in various fields, combining natural and cultural heritage with innovative events and animation.

The development of tourism in cities around the world is of benefit for the local population. Appropriate presentation of tourist sites help tourists to understand the basic need for restoration and preservation of cultural heritage. The opportunities that have emerged make the local economy more entrepreneurial and sustainable. The income from tourism gives possibilities for adequate investments in improving local infrastructure. Cultural exchange of tourists leads to greater tolerance and better understanding of cultural differences in the multicultural societies. The incomes also give better possibilities for preservation and management of cultural heritage. This is extremely important for the sustainability of the sites, attracting large number of tourist. Tourism can provide cultural exchange, development and even an increase in the standard of living in cities (14). In the context of globalization, there are ways in which European cities, such as Stara Zagora, can be renewed, especially when they act as "attracting tourists" destinations, while implementing the processes of developing and preserving the image of places for recreation, entertainment and cultural tourism. The location of the city is of great importance, especially in the context of increased mobility and cultural globalization of tourists, practicing cultural or ecological tourism. These types of tourists are looking mainly for local identity and uniqueness of the city.

Artistic and cultural cities offer stimulation for tourists' creativity through literature, music and cinema. The new technologies developed innovative ways of organizing the economy, new entrepreneurs and industries. On the other hand, the creative city is one of the essential models for urban and sustainable development, and Stara Zagora is on the way to apply this type of specialization in the last 5 years of development, emphasizing on becoming a smart and green city. In order to become and stay attractive for tourists, cities must combine both creative bohemianism and economic success, or so-called three T-s - talent, tolerance and technology which are the bases of the attractiveness of America's most visited urban tourism destinations (15). Big cities and the regions around them provide specific conditions for creation of innovative tourism products through the formation of cultural knowledge that affects only part of the social community in the context of new dimensions of work and lifestyle. This potential of cities will undoubtedly lead to their rapid and creative development.

\section{SUSTAINABLE TOURISM DEVELOPMENT IN LARGE CITIES AND REGIONS WITH RAPID ECONOMIC GROWTH.}

The World Tourism Organization's long-term prognosis for the growth of tourist arrivals predicts an average annual increase of $4.1 \%$ over the next two decades, with the total number of international tourists expected to reach 1.6 billion in 2020 (9). Increasing tourist demand in cities will increase the popularity of urban and regional tourism (16). This trend applies to both organized and business trips. The tourism sustainable consumption pattern is changing (17) - from once a year and long summer recreational holidays to several short tourist trips that take place throughout the year. This fact benefits mainly major cities and metropolitan areas (18), providing interesting tourist innovative sites, variety of recreational and cultural activities, entertainment and attractive shopping sites. The specificity of cities and the higher level of publicity are the basis for the success of any tourist destination (19). Growth dynamics are at the heart of urban tourism as a resource for development of the local economy. As a result, increased intercity and inter-regional competition is observed.

The key factors for developing successful strategies are a good knowledge of the individual profile and specific interests and characteristics of visitors to each city and region. Destination tourism policy must be based on reliable information on tourism trends, visitor activities and tourist mobility within the city and region. It is a fact that urban and regional tourism and related activities are a process driven entirely by innovation and intense competition. On the other hand, there are new trends in consumer behavior - tourists are interested in avant-garde destinations and tourist attractions, as well as in practicing new types and forms of tourism. Therefore, the professionals involved in tourist 
business need to make a lot of efforts in the continuous development of tourism infrastructure, providing innovative services. An example of this is the organization of major cultural or sporting events. The proof is that, thanks to the enlargement of the European Community, the number of tourists visiting Stara Zagora is increasing significantly faster (20).

Traditional cities and regions are those that are not created due to the development of tourism and where this industry has established itself in a changing political, economic, social and cultural environment. Tourism activities interact with other activities in the city as elements of a system of flows and interconnections (19). To some extent, Stara Zagora is a traditional city and region. On the other hand, every city and region, including the district of Stara Zagora, is a dynamic network of different tangible and intangible mobility (21) - tourists, locals, economic activities, financial capitals, investments, culture, knowledge, which constantly reformulate and change the urban space, the organization of tourism, the image of the city and the brand as a tourist destination. Therefore, not only the competitiveness of tourism in the big city and region depends on the attractiveness of natural and anthropogenic resources and the quality of tourism related facilities, but also on the development of these network mobility. Analyzing and evaluating the competitiveness of tourism in a modern city and region requires development of a sustainable model that takes into account the considered factors.

According to recent studies, cities regarded as tourist destinations have transformed from "locations" into "streams" (22;23), representing a complex network of connections and interdependencies between different types of spatial and virtual mobility at local and global levels. Spatial mobility is determined by different factors - increase/decrease of population, migration, growth in consumption of transport services and tourist trips, changes in the structure of the urban economy, tourist flows. Its development implies that cities are in constant motion - examples of this are infrastructure, economic activities, services, hotels, etc., created or closed as a result of this transformation. The movement of local residents, employees, tourists and others occurs within the city and the region and also undergoes dynamic development depending on the territorial structure and dynamics of the urban and regional expansion. In addition to material mobility, cities and regions are also characterized by intangible mobility - financial capitals, investments, information, knowledge, ideas, memories, pictures. The growth of this mobility is accelerated by the development of information and communication technologies.

In practice, tourism is an element of this complex system of mobility. In recent decades, the dynamic development of tourist flows has also influenced the development of welldeveloped economic cities and regions in terms of physical geography of certain destinations. In this context, tourist mobility, both tangible and intangible, affects the dynamic development of other mobility as well. On the other hand, non-tourist mobility (for example increase of foreign investments, development of creative industries, reorganization of urban space, and organization of cultural events in the city) affects the development of urban and regional tourism (rapid emergence of new market tourist segments, expansion of business tourism reach). It is important to note that they affect the way tourists move in the city, how they perceive it and what they experience (24). Therefore, cities and regions can be observed as dynamic "places of movement" $(25 ; 26)$. They are not fixed or motionless, but "playgrounds" whose evolution depends in part on what happens in them (Haldrup, 2004). They can also be observed as derivatives of a multitude of network mobilities - financial capitals, staff, sites, symbols and information (27). This also raises the question of making cities and regions "playgrounds" or, if so, dependent on maintaining this position, which, however, depends on the ever-changing interaction between tourism and political, economic, social, cultural activities. For the functioning of a city and region as a tourist destination, as well as maintaining them at the level of competitiveness, it is important to develop system of mobility and interactions in which they are located, taking into account the influence on the brand of the city and the region, as a tourist destination and its positioning on the international tourism market.(28)

\section{CONCLUSION}

In conclusion, urban and regional tourism is a complex phenomenon of increasing importance for both cities and the tourist business. The tourist industry provides opportunities to increase investments in certain regions, which also benefits the local 
population by increasing jobs and local incomes. This type of tourism is a sustainable source of incomes. Efforts to develop tourism create competition to attract the same market share, which in return requires many destinations to compete with and gain a competitive advantage in offering more and more innovative tourist attractions. Therefore, each city and region with the necessary natural and anthropogenic resources can be transformed into a preferred tourist destination offering urban tourism.

\section{REFERENCES}

1. World Tourism Organization, Global report on city tourism, http://platma.org/publication/global-reportcity-tourism - 02.08.2015

2. European Commission, Towards urban tourism,

http://ec.europa.eu/enterprise/sectors/touris $\mathrm{m} /$ files/studies/towards_quality_tourism_ru ralurbancoastal/iqmurbanen.pdf 27.08.2015

3. World Tourism Organization, World Tourism Barometer, http://mkt.unwto.org/barometer, 17.08.2015

4. Ministry of Tourism, 2014. Strategy for Sustainable Tourism Development in Bulgaria 2014-2030. http://www.tourism.government.bg/sites/to urism.government.bg/files/uploads/strategy -policy/strategy_2014-2030_13_05_2014sled_ms_26_05_2014.pdf

5. Ministry of Tourism, 2018. National Strategy for Sustainable Tourism Development in the Republic of Bulgaria, 2014-2030

http://www.tourism.government.bg/sites/to urism.government.bg/files/documents/2018 -01/nsurtb_2014 -2030.pdf

6. Ministry of Tourism, 2018. Register of Registered Naturalization Management Organizations.

https://ntr.tourism.government.bg/TUnions V2.nsf/orgmanagement.xsp

7. OECD, 2018. OECD Tourism Trends and Policies 2018. https://read.oecdilibrary.org/urban-rural-and-regionaldevelopment/oecd-tourism-trends-andpolicies-2018_tour-2018-en\#page1

8. Master card, Global Destination Cities Index, https://newsroom.mastercard.com/wpcontent/uploads/2015/06/MasterCardGDCI-2015-Final-Reportl.pdf 30.08.2015.
9. World Tourism Organization, http://www2.unwto.org/ - 21.08.2015

10.Kunzmann K., Culture, Creative Industries and Urban Development, Ashgate, London, 2004

11.Judd DR, Fainstein SS. 1999. The Tourist City. Yale University Press, New Haven/London.

12. Castells M., The Rise of the Network Society, Blackwell Publishers, Maiden Massachusetts, 1996.

13. Besculides A., Lee M., McCormick P., 2002. Residents' perceptions of the cultural benefits of tourism. Annals of Tourism Research n. 29, pp. 303-319.

14.Law CM, 1992. Urban tourism and its contribution to economic regeneration. Urban Studies n. 29, pp. 599-618.

15.Lapple D., Thesen zu einer Renaissance der Stadt in der Wissensgesellschaft. 2003. In: Gestring $N$ et al. (eds), Jahrbuch Stadtregionleske, Leske \& Budrich, Opladen, pp. 61-77.

16. Mazanec Josef A., Karl W. Wober (Eds.), 2010. Visiting activities and Inner city tourist mobility, Analysing International City Tourism, sed. Ed., Springer, pp. 213225

17.Becker, C, 2000. Freizeit und Tourismus in Deutsch land: Eine Einfuhrung. In: Institut fur Landerkunde, (ed) Nationalatlas Bundesrepublik Deutschland: Freizeit und Tourismus, vol. 10, Spektrum, Heidelberg, pp. 12-21.

18.Jagnow, E., Wachowiak, H., 2000. Stadtetourismus zwischen Geschaftsreisen und Events. In: Institut fur Landerkunde, (ed) Nationalatlas Bundesrepublik Deutschland: FreizeitundTourismus, vol. 10, Spektrum, Heidelberg, pp. 108 -111.

19.Law, C. M., 1993. Urban tourism: Attracting Visitors to Large Cities, Mansell, London.

20.European Travel Commission, 2008, European Tourism Insights 2007 - Outlook 2008. ETC Marketing Intelligent Report No. $1 / 2008$.

21.Mazanec Josef A., Karl W. Wober (Eds.), 2010. Cities to play: Outlining competitive profiles for European cities. Analysing International City Tourism, sed. Ed., Springer, pp. 171-189

22.Castells, M., 2000. The Space of Flows. In: The Rise of the Network Society. Oxford: Blackwell., pp. 407-459.

23. Manente, M., 2000. Visitor and Mobility Management in an Urban Development Strategy, Tourism, 48 (3), 217- 222. 
24.Baerenholdt, J., Haldrup, M., Larsen, J., Urry, J., 2004. Performing Tourist Places. Aldershot: Ashgate.

25.Hetherington, K., 1997. In Place of Geometry: The Materiality of Place. In: Hetherington, K., Munro, R. (eds) Idea of Difference, Blackwell, Oxford.
26.Crouch, D., 2000. Places Around Us: Embodied Lay Geographies in Leisure and Tourism. Leisure Studies, 19: 63 -76

27.Sheller, M., Urry, J. (eds), 2006. Tourism Mobilities. Places in Play, Places to Play, Routledge, London, pp. 131-142.

28.Coleman, S., Crang M., (eds.) 2002. Tourism:Between Place and Performance. New York: Berghahn. 